\title{
Human Iris Recognition Using Linear Discriminant Analysis Algorithm
}

\author{
Gafar Zen Alabdeen Salh \\ Department of IT \\ Faculty of Computers and IT \\ University of Jeddah, Khulais \\ Jeddah, Saudi Arabia
}

\author{
Abdelmajid Hassan Mansour \\ Department of IT \\ Faculty of Computers and IT \\ University of Jeddah, Khulais \\ Jeddah, Saudi Arabia
}

\author{
Elnazier Abdallah Mohammed \\ Department of CS \\ Faculty of CS and IT \\ Kassala University \\ Kassala, Sudan
}

\begin{abstract}
The paper holding a presentation of a system, which is recognizing peoples through their iris print and that by using Linear Discriminant Analysis method. Which is characterized by the classification of a set of things in groups, these groups are observing a group the features that describe the thing, and is characterized by finding a relationship which give rise to differences in the dimensions of the iris image data from different varieties, and differences between the images in the same class and are less. This Prototype proves a high efficiency on the process of classifying the patterns, the algorithms was applied and tested on MMU database, and it gives good results with a ratio reaching up to $74 \%$.
\end{abstract}

Keywords: linear discriminant analysis, iris recognition, Biometrics, False Rejection Rate, False Acceptance Rate

\section{INTRODUCTION}

Biometrics refers to the identification of human identity via special physiological traits. So scientists have been trying to find solution for designing technologies that can analysis those traits and ultimately distinguish between different people. Some of popular Biometric characteristic are features in fingerprint, speech, DNA, face and different part of it and hand gesture. Among those method face recognition and speaker recognition have been considered more than other during last 2 decades [1].

Iris recognition is one of the most promising approach due to its high reliability for personal identification. The human iris, which is the annular part between the pupil and the white sclera, has a complex pattern. The iris pattern is unique to each person and to each eye and is essentially stable over a lifetime. Also iris pattern of left and right eye is different. Uniqueness, stability makes iris recognition a particularly promising solution to security [3].

The iris is a thin diaphragm, which lies between the cornea and the lens of the human eye. A front on view of iris is shown in fig.1. The iris is perforated close to its centre by a circular aperture known as pupil. The function of the iris is to control the amount of light entering through the pupil. The average diameter of the iris is $12 \mathrm{~mm}$ and the pupil size can vary from $10 \%$ to $80 \%$ of the iris diameter [2].

Iris patterns become interesting as an alternative approach to reliable visual recognition of persons when imaging can be done at distances of less than a meter, and especially when there is a need to search very large databases without incurring any false matches despite a huge number of possibilities. Although small $(11 \mathrm{~mm})$ and sometimes problematic to image, the iris has the great mathematical advantage that its pattern variability among different persons is enormous. In addition, as an internal (yet externally visible) organ of the eye, the iris is well protected from the environment and stable over time. As a planar object its image is relatively insensitive to angle of illumination, and changes in viewing angle cause only affine transformations; even the nonaffine pattern distortion caused by pupillary dilation is readily reversible. Finally, the ease of localizing eyes in faces, and the distinctive annular shape of the iris, facilitate reliable and precise isolation of this feature and the creation of a sizeinvariant representation [7].

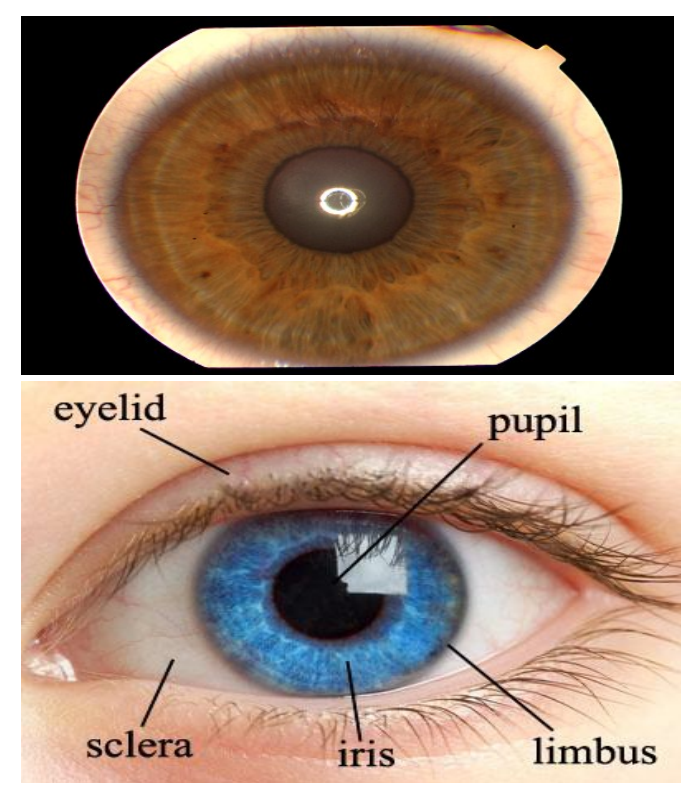

Fig 1: The Human Iris. [12]

In view of iris recognition issue, domestic and overseas scholars have done a lot of in-depth researches, and put forward many effective iris recognition methods. Iris image has high dimensionality, and its feature dimensions often exceed the number of samples, so that the iris image is sparse in high-dimensional spatial distribution. If the original features of iris image are directly entered into the classifier for 
learning, in which the useless and redundant features adversely affect the iris image' recognition rate, resulting in low identify efficiency [4], [5]. In order to solve the "curse of dimensionality" and small sample size issues incurred by iris's high-dimensional feature and improve the iris recognition rate and efficiency, some scholars have proposed the sub-modebased iris recognition algorithm [4], [6]. Sub-mode-based iris recognition algorithm refers to project the high-dimensional iris image onto the low-dimensional subspace by adopting certain dimensionality reduction methods, eliminate the useless and redundant features, and extract the iris features in low-dimensional spaces. Currentiris feature dimensionality reduction techniques consists of the Principal Component Analysis (PCA), Independent Component Analysis (ICA), Linear Discriminant Analysis (LDA), Isometric Feature Mapping (ISOMAP), Locally Linear Embedding algorithm (LLE), Laplacian Eigenmap algorithm (LE), Locality Preserving Projection (LPP) and so on. PCA, ICA, LDA are a class of linear dimension reduction method, which can only extract the global low-dimensional features. It is difficult to find the nonlinear manifold [4].

\section{Overview of Linear Discriminant Analysis (LDA) :}

Linear Discriminant Analysis is a well-known scheme for feature extraction and dimension reduction. It has been used widely in many applications such as face recognition, image retrieval, microarray data classification, etc. Classical LDA projects the data onto a lower-dimensional vector space such that the ratio of the between-class distance to the within-class distance is maximized, thus achieving maximum discrimination. The optimal projection (transformation) can be readily computed by applying the Eigen decomposition on the scatter matrices. An intrinsic limitation of classical LDA is that its objective function requires the nonsingularity of one of the scatter matrices. For many applications, such as face recognition, all scatter matrices in question can be singular since the data is from a very high-dimensional space, and in general, the dimension exceeds the number of data points.

Given a data matrix $A \in \mathbb{I}^{N \times n}$, classical LDA aims to find a transformation that maps each column $a_{i}$ of $A$, for $1 \leq i \leq n$, in the $\mathrm{N}$-dimensional space to a vector $b_{i}$ in the dimensional space. That is

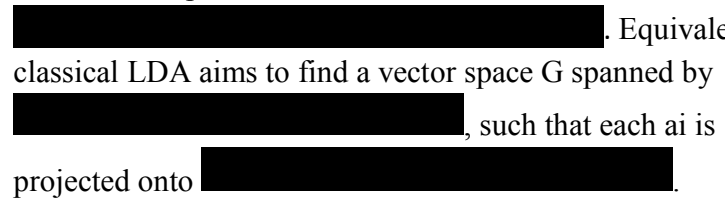

Assume that the original data in $\mathrm{A}$ is partitioned into $\mathrm{k}$ classes as $\mathrm{A}=\{\Pi 1, \cdots, \Pi \mathrm{k}\}$, where

Пi contains ni data points from the ith class, and Classical LDA aims to find the optimal transformation $\mathrm{G}$ such that the class structure of the original high-dimensional space is preserved in the low-dimensional space.
In general, if each class is tightly grouped, but well separated from the other classes, the quality of the cluster is considered to be high. In discriminant analysis, two scatter matrices, called within-class $(\mathrm{Sw})$ and between-class $(\mathrm{Sb})$ matrices, are defined to quantify the quality of the cluster, as follows [4]:
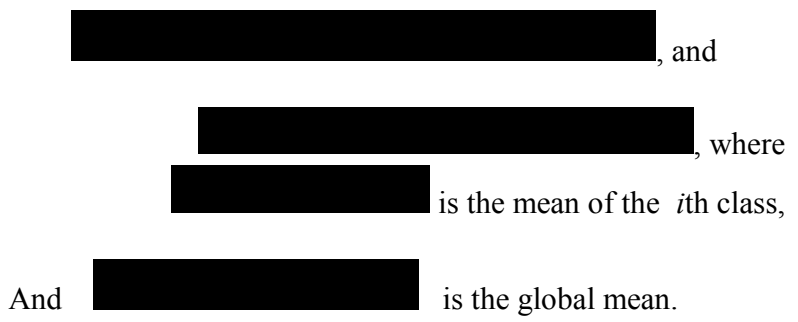

It is easy to verify that trace(Sw) measures the closeness of the vectors within the classes, while trace $(\mathrm{Sb})$ measures the separation between classes. In the low-dimensional space resulting from the linear transformation $G$ (or the linear projection onto the vector space $G$ ), the within-class and between-class matrices become $\mathrm{SbL}=\mathrm{GTSbG}$, and $\mathrm{SwL}=$ GTSwG.

An optimal transformation $\mathrm{G}$ would maximize trace $(\mathrm{SbL})$ and minimize trace(SwL). Common optimizations in classical discriminant analysis:

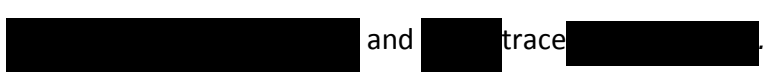

The optimization problems in Eq. (1) are equivalent to the following generalized eigenvalue problem:

. The solution can be obtained by applying an Eigen decomposition to the matrix $S_{w}{ }^{-1} S_{b}$, if Sw is nonsingular, or $S_{b}^{-1} S_{w}$, if $S_{b}$ is nonsingular. There are at most k - 1 eigenvectors corresponding to nonzero eigenvalues, since the rank of the matrix $\mathrm{Sb}$ is bounded from above by $\mathrm{k}-1$. Therefore, the reduced dimension by classical LDA is at most $\mathrm{k}-1$. A stable way to compute the eigen-decomposition is to apply SVD on the scatter matrices. Details can be found in [14].

\section{RELATED WORK}

John Daugman [10] presents the statistical variability that is the basis of iris recognition is analyzed, using new large databases. The principle underlying the recognition algorithm is the failure of a test of statistical independence on iris phase structure encoded by multi-scale quadrature wavelets. Combinatorial complexity of this phase information across deferent persons spans about 249 degrees-of-freedom and generates a discrimination entropy of about $3: 2$ bits $=\mathrm{mm} 2$ over the iris, enabling real-time identi/cation decisions with great enough accuracy to support exhaustive searches through very large databases. This paper presents the results of 9.1 million comparisons among several thousand eye images acquired in trials in Britain, the USA, Japan and Korea.? 2002 Pattern Recognition Society. Published by Elsevier Science Ltd. All rights reserved. Shideh Homayon , [1] proposes 
special type of neural network is used for iris recognition, say LAMSTAR, The LAMSTAR and modified LAMSTAR are applied on CASIA interval database. Both of them are really fast. For instant required time for training was $66.1584 \mathrm{~s}$ and for testing 2.5939 seconds while the accuracy was 99.39\% for regular LAMSTAR and $99.57 \%$ for modified LAMSTAR . Jaydeep N. Kale, Nilesh G. Pardeshi, Vikas N. Nirgude [3] , presents efficient algorithm for iris recognition using Two dimensional (2D) Discrete Fourier Transform (DFT), Algorithm is evaluated with CASIA iris image databases (version 1.0) . M. Z. Rashad1, M. Y. Shams2, O. Nomir2, and R. M. El-Awady3 [8] : proposes an algorithm for iris recognition and classification using a system based on Local Binary Pattern and histogram properties as a statistical approaches for feature extraction, and Combined Learning Vector Quantization Classifier as Neural Network approach for classification, in order to build a hybrid model depends on both features. The localization and segmentation techniques are presented using both Canny edge detection and Hough Circular Transform in order to isolate an iris from the whole eye image and for noise detection. Feature vectors results from LBP is applied to a Combined LVQ classifier with different classes to determine the minimum acceptable performance, and the result is based on majority voting among several LVQ classifier. Different iris datasets CASIA, MMU1, MMU2, and LEI with different extensions and size are presented. Since LBP is working on a grayscale level so colored iris images should be transformed into a grayscale level. The proposed system gives a high recognition rate $99.87 \%$ on different iris datasets compared with other methods. Shibli Nisar, Mushtaq Ali Khan [9]: proposes Iris feature extraction using Mel Frequency Cepstral Coefficient (MFCC). MFCC is originally used for speech and speaker recognition. The MFCC is applied in Iris recognition and the results obtained are very accurate and satisfactory. The system first takes the eye pattern of a person and after converting to 1D signal the MFCC is applied which extracts Iris features. The features are then compared with the features obtained in Enrollment phase, and decision is made after taking Euclidean distance. Ujwalla Gawande, Mukesh Zaveri ,Avichal Kapur [11], proposes Improving Iris Recognition Accuracy by Score Based Fusion Method Iris recognition technology, used to identify individuals by photographing the iris of their eye, The proposed method combines the zero-crossing $1 \mathrm{D}$ wavelet Euler No., and genetic algorithm based for feature extraction. The output from these three algorithms is normalized and their score are fused to decide whether the user is genuine or imposter.

\section{PROPOSED SCHEME}

The proposed work uses the Linear Discriminant Analysis algorithm (LDA) for the purpose of human iris recognition, this system was trained by using MMU1 database it is standard database of iris, on a group of data containing 200 iris image for 20 persons (10 different samples for every person) The system is trained and classified by using the algorithm of LDA, they divided the process of this system into four phases, as shown in Figure2.

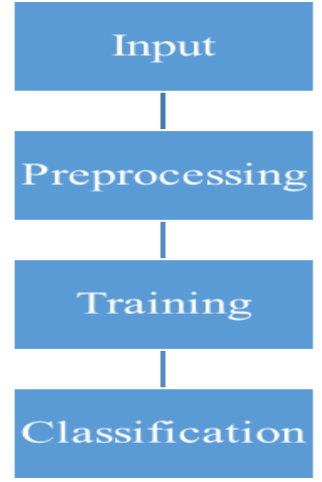

Fig 2. General structure of the system

\section{A. input}

It's the system inputs, and act as the required pattern to train or classification on it, they entered in png or bmp format.

\section{B. Pre-processing}

This phase related to samples configuring of the iris, the image will formatted and optimized, in order to take the optimal shape for training or classifying, they include (Formatting, Cropping, Resizing, Gray scaling, Filtering).

\section{Training:}

The system were trained on 200 image of the iris for 20 person, these image making 20 class, and each class contain 10 left iris image and 10 right iris image, as shown in the Table 1.

\section{TABLE 1: IMAGE USED IN TRAINING PHASE}

\begin{tabular}{|l|l|l|l|}
\hline Class(1) & Iris right (1) & Class(1) & Iris left (1) \\
\hline Class(2) & Iris right (2) & Class(2) & Iris left (2) \\
\hline Class(3) & Iris right (3) & Class(3) & Iris left (3) \\
\hline Class(4) & Iris right (4) & Class(4) & Iris left (4) \\
\hline Class(5) & Iris right (5) & Class(5) & Iris left (5) \\
\hline Class(6) & Iris right (6) & Class(6) & Iris left (6) \\
\hline Class(7) & Iris right (7) & Class(7) & Iris left (7) \\
\hline Class(8) & Iris right (8) & Class(8) & Iris left (8) \\
\hline Class(9) & Iris right (9) & Class(9) & Iris left (9) \\
\hline Class(10) & Iris right (10) & Class(10) & Iris left (10) \\
\hline Class(11) & Iris right (11) & Class(11) & Iris left (11) \\
\hline Class(12) & Iris right (12) & Class(12) & Iris left (12) \\
\hline Class(13) & Iris right (13) & Class(13) & Iris left (13) \\
\hline Class(14) & Iris right (14) & Class(14) & Iris left (14) \\
\hline Class(15) & Iris right (15) & Class(15) & Iris left (15) \\
\hline Class(16) & Iris right (16) & Class(16) & Iris left (16) \\
\hline Class(17) & Iris right (17) & Class(17) & Iris left (17) \\
\hline Class(18) & Iris right (18) & Class(18) & Iris left (18) \\
\hline Class(19) & Iris right (19) & Class(19) & Iris left (19) \\
\hline Class(20) & Iris right (20) & Class(20) & Iris left (20) \\
\hline
\end{tabular}

\section{E. Classification}

On this phase they taken a decision, where the recognition is done, and identification of the entered image to which specific class it belong, by using the data resulted from the training process. Then entered pattern will be compared with features of the 20 class that exist on the system by using the Linear Discriminant Analysis algorithm (LDA). 


\section{RESULTS OF TESTING THE SYSTEM ON MMU1 DATABASE OF IRIS}

The Multimedia University has developed a small data set of 450 iris images (MMU). They was captured through one of the most common iris recognition cameras presently functioning (LG Iris Access 2200). This is a semi-automated camera that operates at the range of 7-25 $\mathrm{cm}$. Further, a new data set (MMU2) comprised of 995 iris images has been released and another common iris recognition camera (Panasonic BM-ET100US Authenticam) was used. The iris images are from 100 volunteers with different ages and nationalities. They come from Asia, Middle East, Africa and Europe and each of them contributed with five iris images from each eye. [15]

The test was over twenty people and each person has ten iris images under different illuminations and distances from the camera.

\section{Recognition of group 1}

After testing the image of the group number 1, the system was recognized to 8 sample out of 10 , as shown in the Table 2 and Fig 3.

Table 2: RECOGNITION OFGROUP 1

\begin{tabular}{|c|c|c|c|c|}
\hline & & Frequency & Percent & $\begin{array}{c}\text { Valid } \\
\text { Percent }\end{array}$ \\
\hline \multicolumn{2}{|r|}{$\begin{array}{c}\text { false } \\
\text { Classification }\end{array}$} & 2 & 20.0 & 20.0 \\
\hline \multicolumn{2}{|r|}{$\begin{array}{c}\text { True } \\
\text { Classification }\end{array}$} & 8 & 80.0 & 80.0 \\
\hline \multicolumn{2}{|r|}{ Total } & 10 & 100.0 & 100.0 \\
\hline \multicolumn{5}{|l|}{9} \\
\hline 8 & & \\
\hline 7 & & \multicolumn{3}{|c|}{ True Classification } \\
\hline 6 & & \\
\hline 5 & & \multicolumn{3}{|c|}{ False Classification } \\
\hline \multicolumn{5}{|l|}{4} \\
\hline \\
\hline \multicolumn{5}{|l|}{2} \\
\hline \multicolumn{5}{|l|}{1} \\
\hline 0 & True Classification & \multicolumn{3}{|c|}{ False Classification } \\
\hline
\end{tabular}

Fig 3. Recognition of group 1

\section{Recognition of group 2}

After testing the image of the group number 2, the system was recognized to 8 sample out of 10 , as shown in the Table 3 and Fig 4.

Table 3: RECOGNITION OFGROUP 2

\begin{tabular}{|cc|c|c|c|}
\hline & Frequency & Percent & $\begin{array}{c}\text { Valid } \\
\text { Percent }\end{array}$ \\
\hline Valid & $\begin{array}{c}\text { false } \\
\text { Classification }\end{array}$ & 2 & 20.0 & 20.0 \\
\hline $\begin{array}{c}\text { True } \\
\text { Classification }\end{array}$ & 8 & 80.0 & 80.0 \\
\hline Total & 10 & 100.0 & 100.0 \\
\hline
\end{tabular}

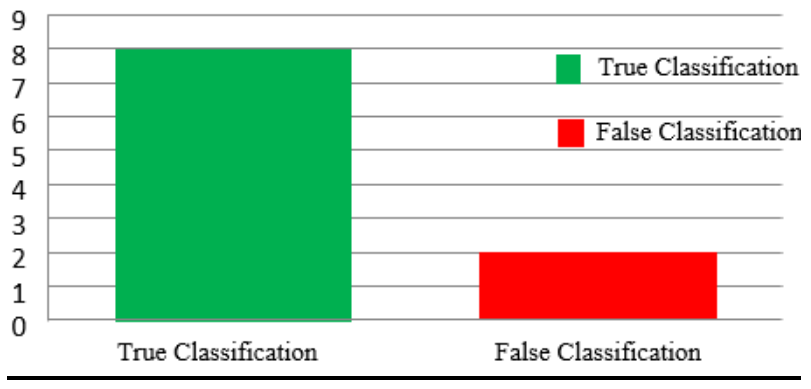

Fig4. Recognition of group 2

\section{Recognition of group 3}

After testing the image of the group number 3, the system was recognized to 9 sample out of 10 , as shown in the Table 4 and Fig 5.

Table 4: RECOGNITION OFGROUP 3

\begin{tabular}{|c|c|c|c|}
\hline & Frequency & Percent & $\begin{array}{c}\text { Valid } \\
\text { Percent }\end{array}$ \\
\hline $\begin{array}{cc}\text { Valid } & \text { false } \\
& \text { Classification }\end{array}$ & 1 & 10.0 & 10.0 \\
\hline $\begin{array}{c}\text { True } \\
\text { Classification }\end{array}$ & 9 & 90.0 & 90.0 \\
\hline Total & 10 & 100.0 & 100.0 \\
\hline
\end{tabular}

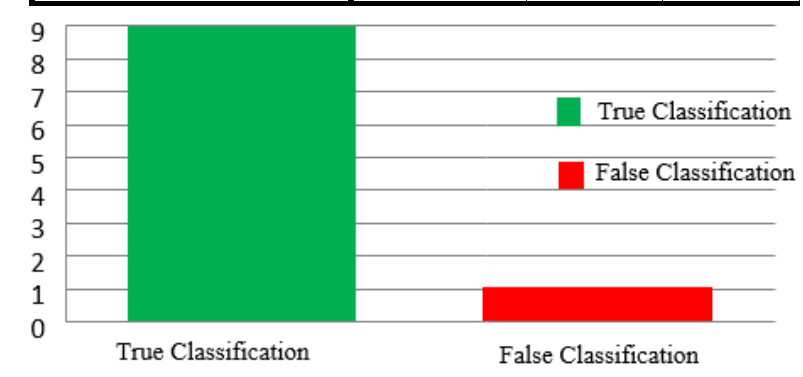

Fig 5. Recognition of group 3

\section{A. Recognition of group 4}

After testing the image of the group number 4, the system was recognized to 8 sample out of 10, as shown in the Table 5 and Fig 6.

Table 5: RECOGNITION OFGROUP 4

\begin{tabular}{|c|c|c|c|}
\hline & Frequency & Percent & $\begin{array}{c}\text { Valid } \\
\text { Percent }\end{array}$ \\
\hline $\begin{array}{cc}\text { Valid } & \text { false } \\
& \text { Classification }\end{array}$ & 2 & 20.0 & 20.0 \\
\hline $\begin{array}{c}\text { True } \\
\text { Classification }\end{array}$ & 8 & 80.0 & 80.0 \\
\hline Total & 10 & 100.0 & 100.0 \\
\hline
\end{tabular}




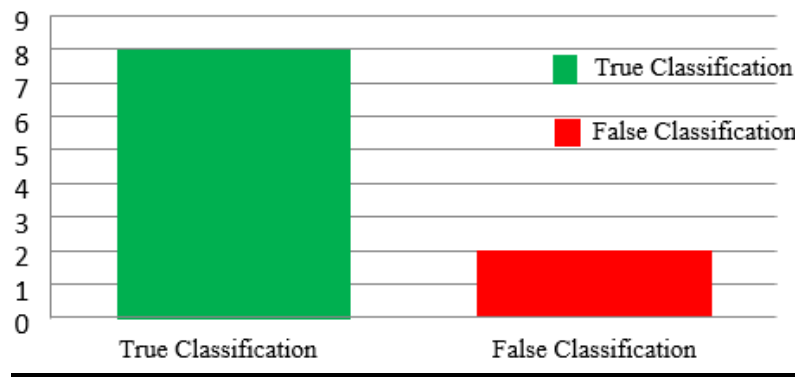

Fig 6. Recognition of group 4

\section{A. Recognition of group 5}

After testing the image of the group number 5, the system was recognized to 8 sample out of 10, as shown in the Table 6 and Fig 7.

Table 6: RECOGNITION OFGROUP 5

\begin{tabular}{|c|c|c|c|c|}
\hline & & Frequency & Percent & $\begin{array}{c}\text { Valid } \\
\text { Percent }\end{array}$ \\
\hline Valid & $\begin{array}{c}\text { false } \\
\text { Classification }\end{array}$ & 2 & 20.0 & 20.0 \\
\hline & $\begin{array}{c}\text { True } \\
\text { Classification }\end{array}$ & 8 & 80.0 & 80.0 \\
\hline & Total & 10 & 100.0 & 100.0 \\
\hline
\end{tabular}

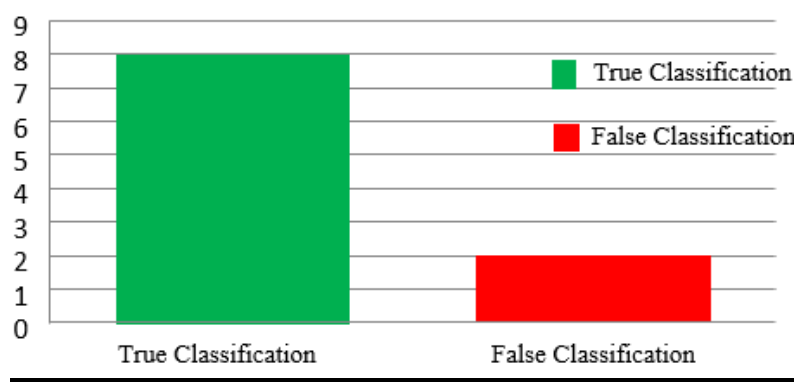

Fig 7. Recognition of group 5

\section{Recognition of group 6}

After testing the image of the group number 6 , the system was recognized to 6 sample out of 10, as shown in the Table 7 and Fig 8 .

Table 7: RECOGNITION OF GROUP 6

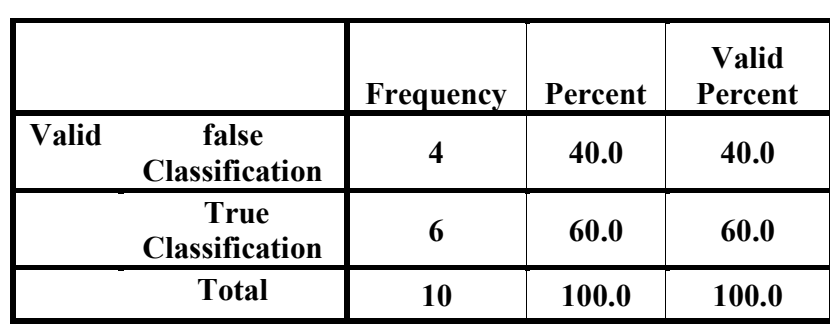

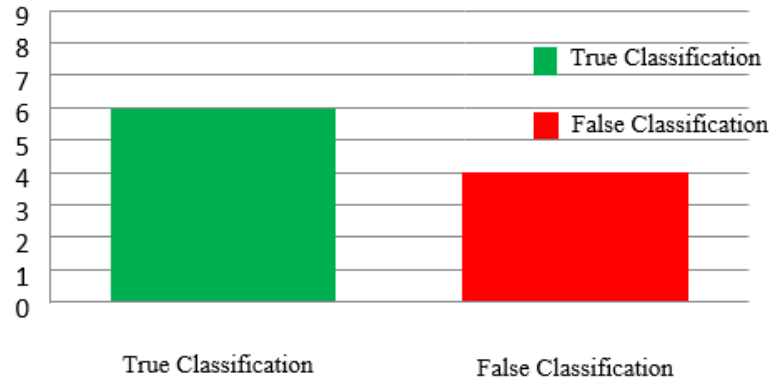

Fig 8. Recognition of group 6

\section{Recognition of group 7}

After testing the image of the group number 7, the system was recognized to 7 sample out of 10 , as shown in the Table 8 and Fig 9.

Table 8: RECOGNITION OFGROUP 7

\begin{tabular}{|c|c|c|c|}
\hline & Frequency & Percent & $\begin{array}{l}\text { Valid } \\
\text { Percent }\end{array}$ \\
\hline $\begin{array}{lc}\text { Valid } & \text { false } \\
& \text { Classification }\end{array}$ & 3 & 30.0 & 30.0 \\
\hline $\begin{array}{c}\text { True } \\
\text { Classification }\end{array}$ & 7 & 70.0 & 70.0 \\
\hline Total & 10 & 100.0 & 100.0 \\
\hline
\end{tabular}

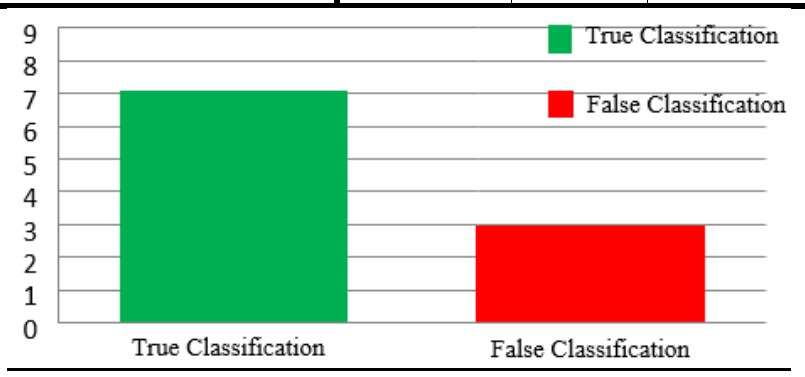

Fig 9. Recognition of group 7

\section{Recognition of group 8}

After testing the image of the group number 8 , the system was recognized to 8 sample out of 10, as shown in the Table 9 and Fig 10.

Table 9: RECOGNITION OFGROUP 8

\begin{tabular}{|cc|c|c|c|}
\hline & Frequency & Percent & $\begin{array}{c}\text { Valid } \\
\text { Percent }\end{array}$ \\
\hline Valid & $\begin{array}{c}\text { false } \\
\text { Classification }\end{array}$ & 2 & 20.0 & 20.0 \\
\hline $\begin{array}{c}\text { True } \\
\text { Classification }\end{array}$ & 8 & 80.0 & 80.0 \\
\hline Total & 10 & 100.0 & 100.0 \\
\hline
\end{tabular}




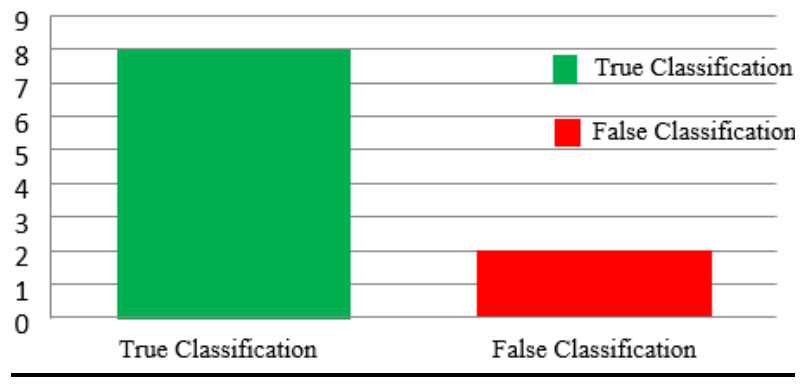

Fig 10. Recognition of group 8

\section{Recognition of group 9}

After testing the image of the group number 9, the system was recognized to 8 sample out of 10 , as shown in the Table 10 and Fig 11.

Table 10: RECOGNITION OFGROUP 9

\begin{tabular}{|cc|c|c|c|}
\hline & Frequency & Percent & $\begin{array}{c}\text { Valid } \\
\text { Percent }\end{array}$ \\
\hline Valid & $\begin{array}{c}\text { false } \\
\text { Classification }\end{array}$ & 2 & 20.0 & 20.0 \\
\hline $\begin{array}{c}\text { True } \\
\text { Classification }\end{array}$ & 8 & 80.0 & 80.0 \\
\hline Total & 10 & 100.0 & 100.0 \\
\hline
\end{tabular}

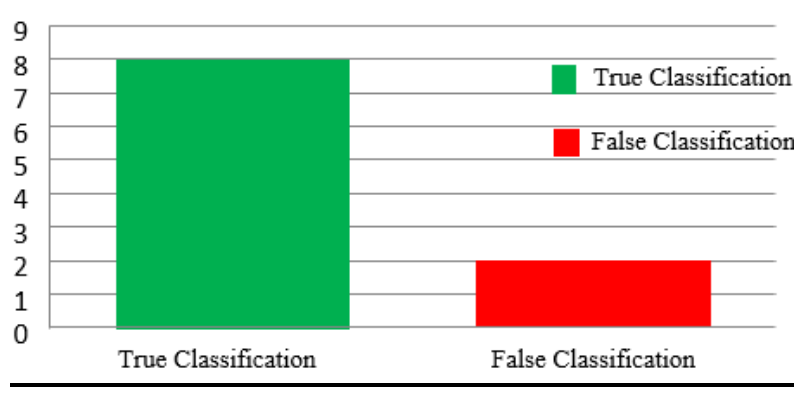

Fig 11. Recognition of group 9

\section{Recognition of group 10}

After testing the image of the group number 10, the system was recognized to 8 sample out of 10 , as shown in the Table 11 and Fig 12.

Table 11: RECOGNITION OFGROUP 10

\begin{tabular}{|c|c|c|c|c|}
\hline & & Frequency & Percent & $\begin{array}{l}\text { Valid } \\
\text { Percent }\end{array}$ \\
\hline Valid & $\begin{array}{c}\text { false } \\
\text { Classification } \\
\end{array}$ & 2 & 20.0 & 20.0 \\
\hline & $\begin{array}{c}\text { True } \\
\text { Classification }\end{array}$ & 8 & 80.0 & 80.0 \\
\hline & Total & 10 & 100.0 & 100.0 \\
\hline
\end{tabular}

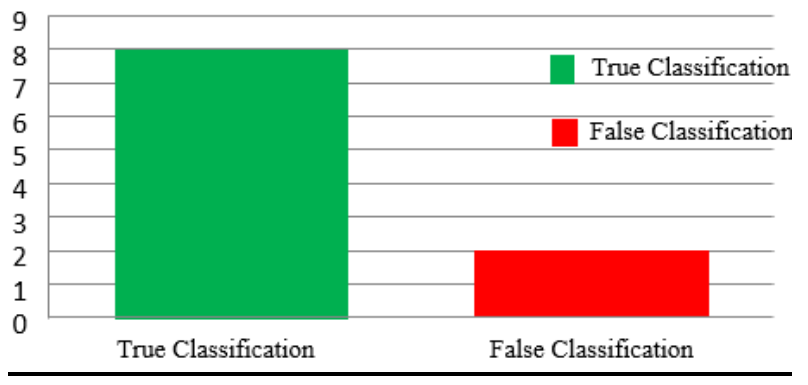

Fig 12. Recognition of group 10

\section{Recognition of group 11}

After testing the image of the group number 11, the system was recognized to 7 sample out of 10 , as shown in the Table 12 and Fig 13

Table 12: RECOGNITION OFGROUP 11

\begin{tabular}{|c|c|c|c|}
\hline & Frequency & Percent & $\begin{array}{l}\text { Valid } \\
\text { Percent }\end{array}$ \\
\hline $\begin{array}{cc}\text { Valid } & \text { false } \\
& \text { Classification }\end{array}$ & 3 & 30.0 & 30.0 \\
\hline $\begin{array}{c}\text { True } \\
\text { Classification }\end{array}$ & 7 & 70.0 & 70.0 \\
\hline Total & 10 & 100.0 & 100.0 \\
\hline
\end{tabular}

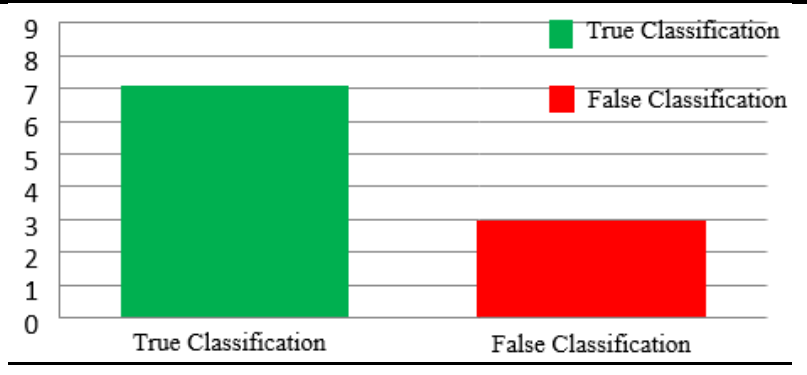

Fig 13. Recognition of group 11

\section{Recognition of group 12}

After testing the image of the group number 8, the system was recognized to 7 sample out of 10, as shown in the Table 13 and Fig 14.

Table 13: RECOGNITION OFGROUP 12

\begin{tabular}{|c|c|c|c|}
\hline & Frequency & Percent & $\begin{array}{c}\text { Valid } \\
\text { Percent }\end{array}$ \\
\hline $\begin{array}{cc}\text { Valid } & \text { false } \\
& \text { Classification }\end{array}$ & 3 & 30.0 & 30.0 \\
\hline $\begin{array}{c}\text { True } \\
\text { Classification }\end{array}$ & 7 & 70.0 & 70.0 \\
\hline Total & 10 & 100.0 & 100.0 \\
\hline
\end{tabular}




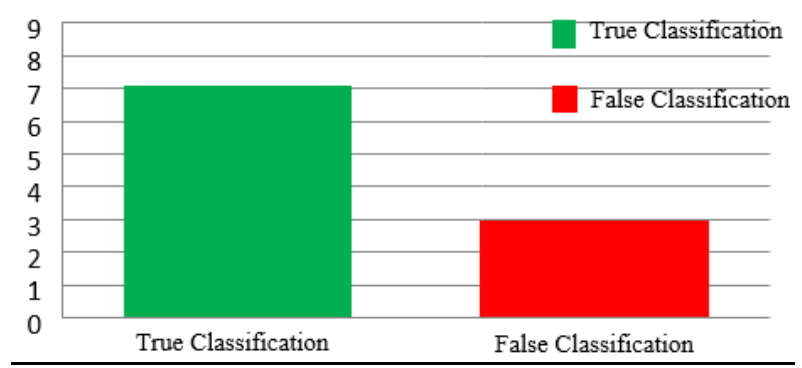

Fig 14. Recognition of group 12

\section{Recognition of group 13}

After testing the image of the group number 13, the system was recognized to 7 sample out of 10 , as shown in the Table 14 and Fig 15.

Table 14: RECOGNITION OFGROUP 13

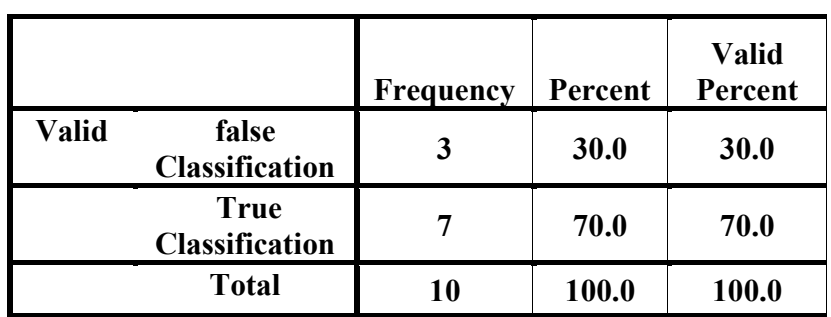

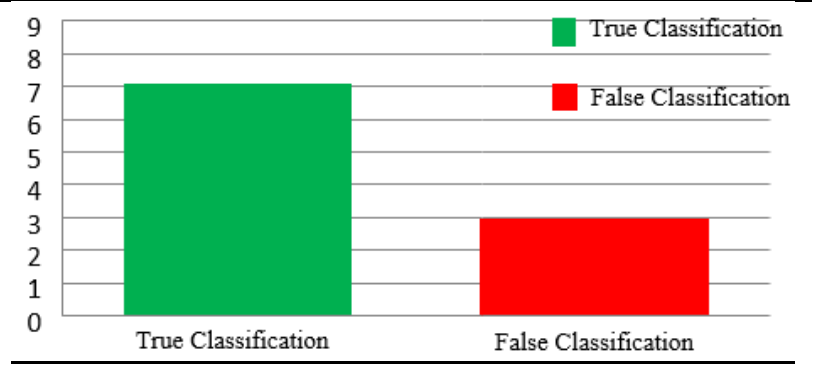

Fig 15. Recognition of group 13

\section{Recognition of group 14}

After testing the image of the group number 14, the system was recognized to 9 sample out of 10 , as shown in the Table 15 and Fig 16.

Table 15: RECOGNITION OFGROUP 14

\begin{tabular}{|c|c|c|c|}
\hline & Frequency & Percent & $\begin{array}{c}\text { Valid } \\
\text { Percent }\end{array}$ \\
\hline $\begin{array}{cc}\text { Valid } & \text { false } \\
& \text { Classification }\end{array}$ & 1 & 10.0 & 10.0 \\
\hline $\begin{array}{c}\text { True } \\
\text { Classification }\end{array}$ & 9 & 90.0 & 90.0 \\
\hline Total & 10 & 100.0 & 100.0 \\
\hline
\end{tabular}

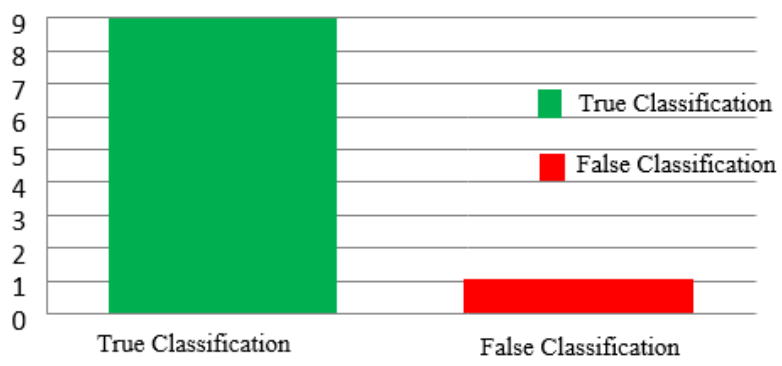

Fig 16. Recognition of group 14

\section{Recognition of group 15}

After testing the image of the group number 15, the system was recognized to 7 sample out of 10 , as shown in the Table 16 and Fig 17.

Table 16: RECOGNITION OFGROUP 15

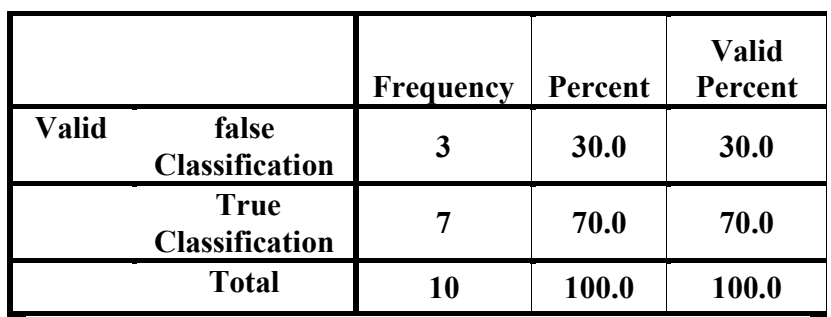

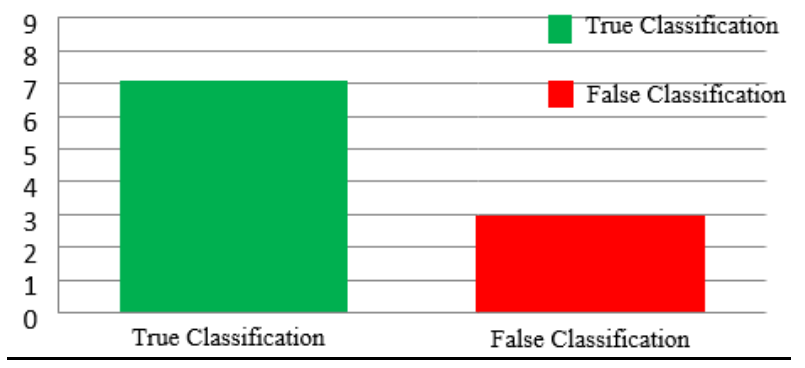

Fig 17. Recognition of group 15

\section{Recognition of group 16}

After testing the image of the group number 16, the system was recognized to 7 sample out of 10 , as shown in the Table 17 and Fig 18.

Table 17: RECOGNITION OFGROUP 16

\begin{tabular}{|c|c|c|c|}
\hline & Frequency & Percent & $\begin{array}{c}\text { Valid } \\
\text { Percent } \\
\end{array}$ \\
\hline $\begin{array}{lc}\text { Valid } & \text { false } \\
& \text { Classification }\end{array}$ & 3 & 30.0 & 30.0 \\
\hline $\begin{array}{c}\text { True } \\
\text { Classification }\end{array}$ & 7 & 70.0 & 70.0 \\
\hline Total & 10 & 100.0 & 100.0 \\
\hline
\end{tabular}




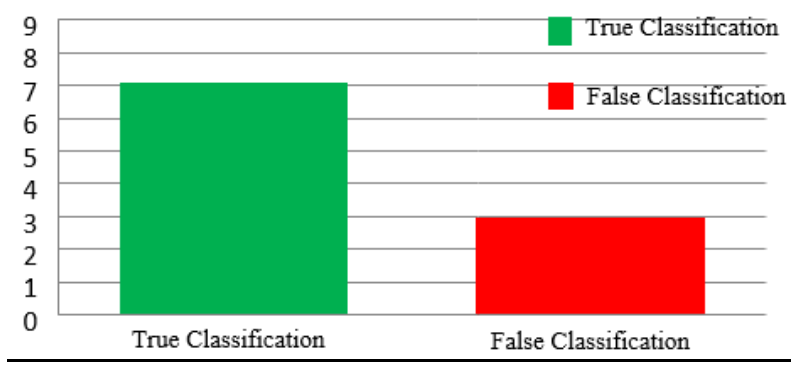

Fig 18. Recognition of group 16

\section{Recognition of group 17}

After testing the image of the group number 17, the system was recognized to 8 sample out of 10 , as shown in the Table 18 and Fig 19.

Table18: RECOGNITION OFGROUP 17

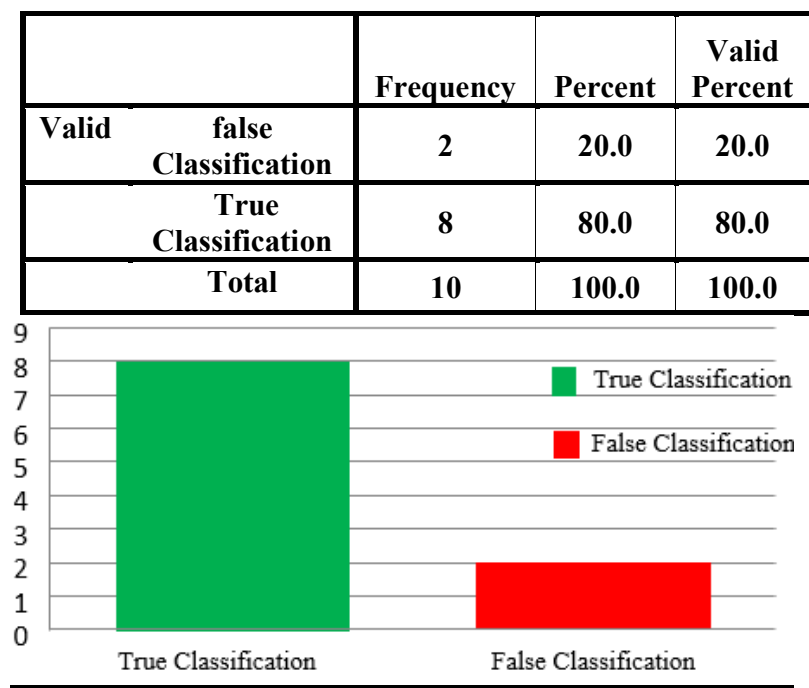

Fig 19. Recognition of group 17

\section{A. Recognition of group 18}

After testing the image of the group number 18, the system was recognized to 8 sample out of 10 , as shown in the Table 19 and Fig 20.

Table 19: RECOGNITION OFGROUP 18

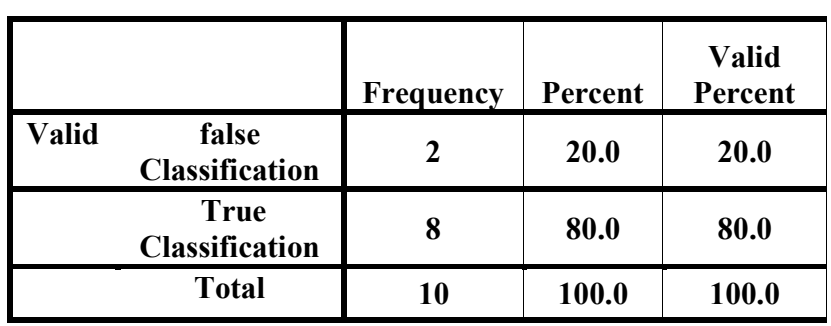

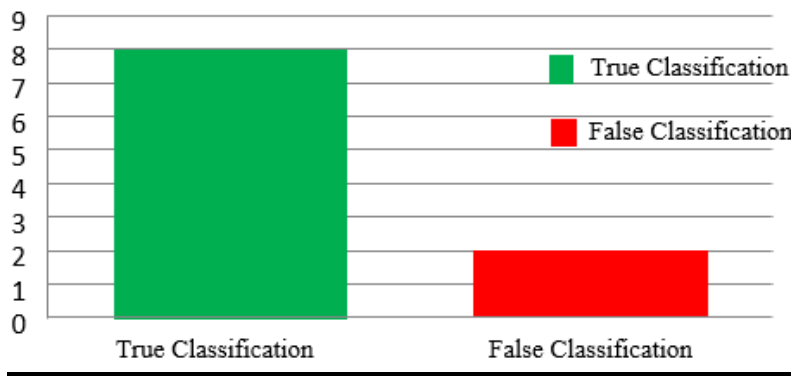

Fig 20. Recognition of group 18

\section{Recognition of group 19}

After testing the image of the group number 19, the system was recognized to 9 sample out of 10 , as shown in the Table 20 and Fig 21.

Table 20: RECOGNITION OFGROUP 8

\begin{tabular}{|c|c|c|c|}
\hline & Frequency & Percent & $\begin{array}{c}\text { Valid } \\
\text { Percent }\end{array}$ \\
\hline Valid $\begin{array}{c}\text { false } \\
\text { Classification }\end{array}$ & 1 & 10.0 & 10.0 \\
\hline $\begin{array}{c}\text { True } \\
\text { Classification }\end{array}$ & 9 & 90.0 & 90.0 \\
\hline Total & 10 & 100.0 & 100.0 \\
\hline
\end{tabular}

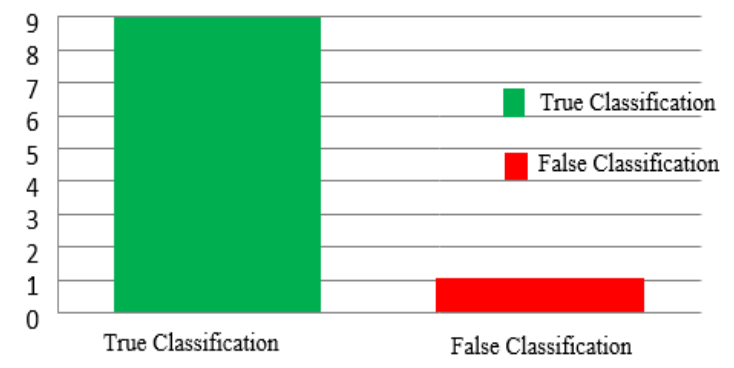

Fig 21. Recognition of group 21

\section{$X X$. Recognition of group 20}

After testing the image of the group number 20, the system was recognized to 7 sample out of 10, as shown in the Table 21 and Fig 22.

Table 21: RECOGNITION OFGROUP 20

\begin{tabular}{|c|c|c|c|}
\hline & Frequency & Percent & $\begin{array}{c}\text { Valid } \\
\text { Percent }\end{array}$ \\
\hline $\begin{array}{cc}\text { Valid } & \text { false } \\
& \text { Classification }\end{array}$ & 3 & 30.0 & 30.0 \\
\hline $\begin{array}{c}\text { True } \\
\text { Classification } \\
\end{array}$ & 7 & 70.0 & 70.0 \\
\hline Total & 10 & 100.0 & 100.0 \\
\hline
\end{tabular}




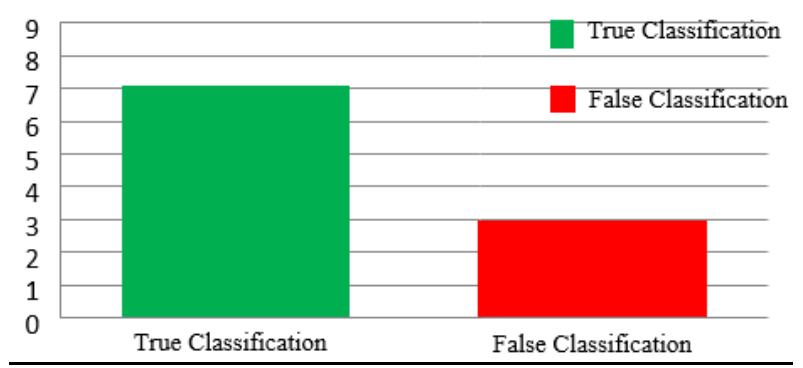

Fig 22. Recognition of group 20

\section{Recognition of all groups}

After testing the image of all groups, the system was recognized to 148 sample out of 200 , as shown in the Table 22 and Fig 23.

Table 22: RECOGNITION OF ALL GROUPS

\begin{tabular}{|c|c|c|c|}
\hline & Frequency & Percent & $\begin{array}{c}\text { Valid } \\
\text { Percent }\end{array}$ \\
\hline $\begin{array}{cc}\text { Valid } & \text { false } \\
& \text { Classification } \\
\end{array}$ & 52 & 26.0 & 26.0 \\
\hline $\begin{array}{c}\text { True } \\
\text { Classification }\end{array}$ & 148 & 74.0 & 74.0 \\
\hline total & 10 & 100.0 & 100.0 \\
\hline
\end{tabular}

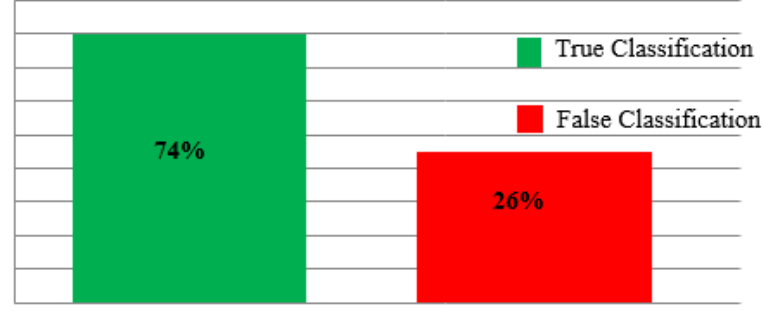

Fig 23. Recognition of all groups

40 samples were selected to measure the performance of iris recognition system .20 iris to test iris False Acceptance Rate (FAR) and 20 to test the False Rejection Rate FRR, and the results were as follows:

\section{Table 23: CALCULATION OF FALSE ACCEPTANCE} \& FALSE REJECTION RATE

\begin{tabular}{|c|c|c|}
\hline & $\begin{array}{c}\text { False } \\
\text { Rejection }\end{array}$ & $\begin{array}{c}\text { False } \\
\text { Acceptance }\end{array}$ \\
\hline $\mathbf{1}$ & $\mathbf{T}$ & $\mathbf{T}$ \\
\hline $\mathbf{2}$ & $\mathbf{T}$ & $\mathbf{T}$ \\
\hline 3 & $\mathbf{T}$ & $\mathbf{F}$ \\
\hline 4 & $\mathbf{T}$ & $\mathbf{T}$ \\
\hline $\mathbf{5}$ & $\mathbf{T}$ & $\mathbf{F}$ \\
\hline $\mathbf{6}$ & $\mathbf{F}$ & $\mathbf{T}$ \\
\hline 7 & $\mathbf{T}$ & $\mathbf{T}$ \\
\hline $\mathbf{8}$ & $\mathbf{T}$ & $\mathbf{T}$ \\
\hline $\mathbf{9}$ & $\mathbf{T}$ & $\mathbf{T}$ \\
\hline $\mathbf{1 0}$ & $\mathbf{T}$ & $\mathbf{T}$ \\
\hline 11 & $\mathbf{T}$ & $\mathbf{T}$ \\
\hline
\end{tabular}

\begin{tabular}{|c|c|c|}
\hline 12 & $\mathbf{T}$ & $\mathbf{T}$ \\
\hline 13 & $\mathbf{T}$ & $\mathbf{T}$ \\
\hline 14 & $\mathbf{T}$ & $\mathbf{T}$ \\
\hline 15 & $\mathbf{T}$ & $\mathbf{F}$ \\
\hline 16 & $\mathbf{T}$ & $\mathbf{T}$ \\
\hline 17 & $\mathbf{T}$ & $\mathbf{T}$ \\
\hline 18 & $\mathbf{T}$ & $\mathbf{T}$ \\
\hline 19 & $\mathbf{T}$ & $\mathbf{T}$ \\
\hline 20 & $\mathbf{T}$ & $\mathbf{T}$ \\
\hline
\end{tabular}

The False Acceptance Rate $(\mathrm{FAR})=1 / 20 * 100=5 \%, \quad$ as shown in Table 24 .and Fig 24.

Table 24: FALSE ACCEPTANCE RATE

\begin{tabular}{|c|c|c|c|}
\hline & Frequency & Percent & $\begin{array}{c}\text { Valid } \\
\text { Percent }\end{array}$ \\
\hline Valid invalid & 1 & 5.0 & 5.0 \\
\hline valid & 19 & 95.0 & 94.0 \\
\hline total & 20 & 100.0 & 100.0 \\
\hline
\end{tabular}

The False Rejection Rate $($ FRR $)=3 / 20 * 100=15 \%$, as shown in Table 25 and Fig 24.

Table 25: False Rejection Rate FRR

\begin{tabular}{|rc|c|c|c|}
\hline & Frequency & Percent & $\begin{array}{c}\text { Valid } \\
\text { Percent }\end{array}$ \\
\hline Valid & invalid & 3 & 15.0 & 5.01 \\
\hline & valid & 17 & 85.0 & 84.0 \\
\hline total & 20 & 100.0 & 100.0 \\
\hline
\end{tabular}

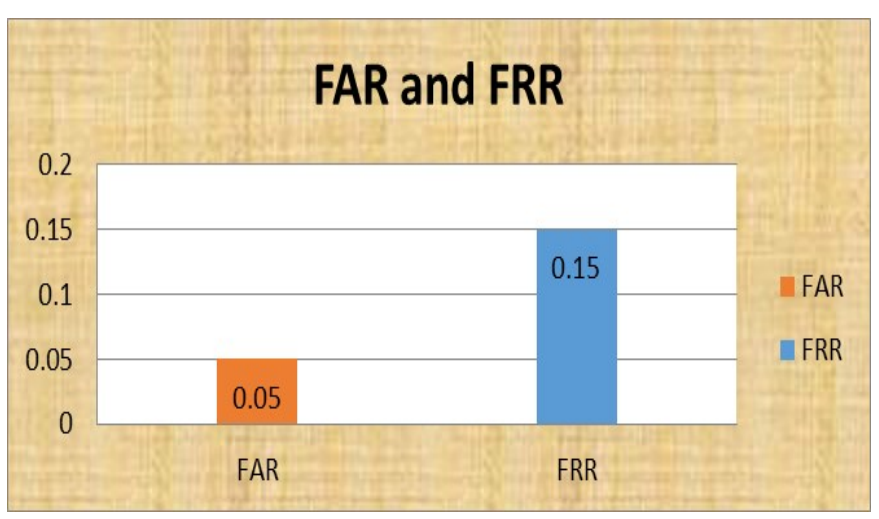

Fig 24. Result of False Acceptance \& False Rejection Rate 


\section{CONCULSION}

The paper aim to increase efficiently of iris recognition process, which was reached recognition rate amounted to $74 \%$, the samples are trained and tested on standard database of iris (MMU), as we have acquired False Acceptance Rate, FAR) is $5 \%$, a ratio less than the False Rejection Rate (FRR) , which amounted to $(15 \%$ )therefore, we can say that the linear discriminate analysis algorithm (LDA ) highly efficient in identifying the iris recognition .

\section{References}

[1] Shideh Homayon, IRIS RECOGNITION FOR PERSONAL IDENTIFICATION USING LAMSTAR NEURALNETWORK , International Journal of Computer Science \& Information Technology (IJCSIT) Vol 7, No 1, February 2015. DOI:10.5121/ijcsit.2015.7101.

[2] Ms. Aparna G. Gale, DR. S. S. Salankar, A Review On Advance Methods Of Feature Extraction In Iris Recognition System, IOSR Journal of Electrical and Electronics Engineering (IOSR-JEEE) e-ISSN: 22781676, p-ISSN: 2320-3331 PP 65-70 www.iosrjournals.org, International Conference on Advances in Engineering \& Technology - 2014 (ICAET2014) 65 | Page

[3] Jaydeep N. Kale, Nilesh G. Pardeshi, Vikas N. Nirgude, Improved Iris Recognition using Discrete Fourier Transform, International Journal of Computer Applications (0975 - 8887) International Conference on Recent Trends in engineering \& Technology 2013(ICRTET'2013)

[4] Yongqiang LI, Iris Recognition Algorithm based on MMC-SPP ,International Journal of Signal Processing, Image Processing and Pattern Recognition Vol. 8, No. 2 (2015),pp.1-10 http://dx.doi.org/10.14257/ijsip.2015.8.2.01

[5] Z. N. Sun and T. N.Tan,"Ordinal Measures for Iris Recognition",IEEE Trans. Pattern Analysis and Machine Intelligence, vol. 31, no. 12, (2009), pp.2211-2226.

[6] Z. HeandL. Lv, "Iris feature extraction and recognition based on ICA-MJE and SVM",Computer Applications, vol.27, no. 6, (2007), pp.1505-1507.

[7] John Daugman, How Iris Recognition Works, IEEE TRANSACTIONS ON CIRCUITS AND SYSTEMS FOR VIDEO TECHNOLOGY, VOL. 14, NO. 1, JANUARY 2004 .pp 21-30.

[8] M. Z. Rashad1, M. Y. Shams2, O. Nomir2, and R. M. ElAwady3 ,IRIS RECOGNITION BASED ON LBP AND COMBINED LVQ CLASSIFIER, International Journal of Computer Science \& Information Technology (IJCSIT) Vol 3, No 5, Oct 2011, DOI : $10.5121 /$ ijcsit.2011.3506

[9] Shibli Nisar, Mushtaq Ali Khan, Muhammad Usman , Iris Recognition using Mel Fequency Cepstral Coefficient , International Journal of Engineering Research (ISSN:2319-6890)(online),2347-5013(print) Volume No.3, Issue No.2, pp : 100-103

[10] J. Daugman, "The importance of being random: statistical principles of iris recognition", Pattern Recognition Society, Vol. 36, pp. 279-291, 2003.
[11] Ujwalla Gawande, Mukesh Zaveri ,Avichal Kapur, Improving Iris Recognition Accuracy by Score Based Fusion Method, International Journal of Advancements in Technology (IJoAT) http://ijict.org/ ISSN 0976-4860, Vol 1, No 1 (June 2010) CIJoAT .

[12] Sangini Shah, Ankita Mandowara, Mitesh Patel , IRIS SEGMENTATION AND RECOGNITION FOR HUMAN IDENTIFICATION, INTERNATIONAL JOURNAL OF INNOVATIVE RESEARCH IN TECHNOLOGY, (C) 2014 IJIRT | Volume 1 Issue 7 | ISSN: 2349-6002

[13] VO Dinh Minh Nhat and SungYoung Lee (2007). Imagebased Subspace Analysis for Face Recognition, Face Recognition, Kresimir Delac and Mislav Grgic (Ed.), ISBN: 978-3-902613-03-5, InTech, Available from:http://www.intechopen.com/books/face_recognition /image-based_subspace_analysis_for_face_recognition

[14] J. Ye, R. Janardan, and Q. Li, "Two-dimensional linear discriminant analysis," Advances in Neural Information Processing Systems (NIPS2004), 17:1569-1576, 2004.

[15] "MMU Iris Image Database: Multimedia University," http://pesona.mmu.edu.my/ccteo; 2004

\section{Authors Profile}

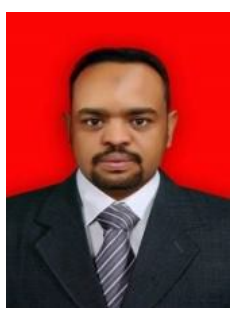

Dr. Gafar Zen Alabdeen Salh Hassan, Assistant Professor, Department of Computers and Information Technology, University of Jeddah, Faculty of Computers and Information Technology, Khulais, Jeddah, Saudi Arabia..

Permanent Address: Department of Information Technology, Faculty of computer Science and Information Technology, Alneelain University, Khartoum, Sudan.

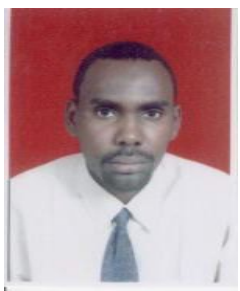

Dr. Abdelmajid Hassan Mansour Emam, Assistant Professor, Department of Computers and Information Technology, University of Jeddah, Faculty of Computers and Information Technology, Khulais, Jeddah, Saudi Arabia.

Permanent Address: Department of Information Technology, Faculty of computer Science and Information Technology, Alneelain University, Khartoum, Sudan.

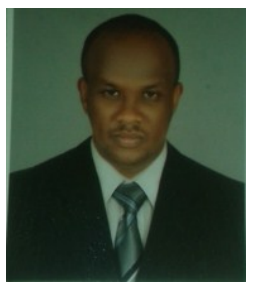

Elnazier Abdallah Mohammed Elhassan, Lecturer, Department of computer Science, Faculty of computer Science and Information Technology, Kassala University, Kassala, Sudan 